The visor (see Figure) consists of a transparent mesh of steel rings, so closely linked together that only the most minute particle could pass through its meshes, and then only if it were struck at

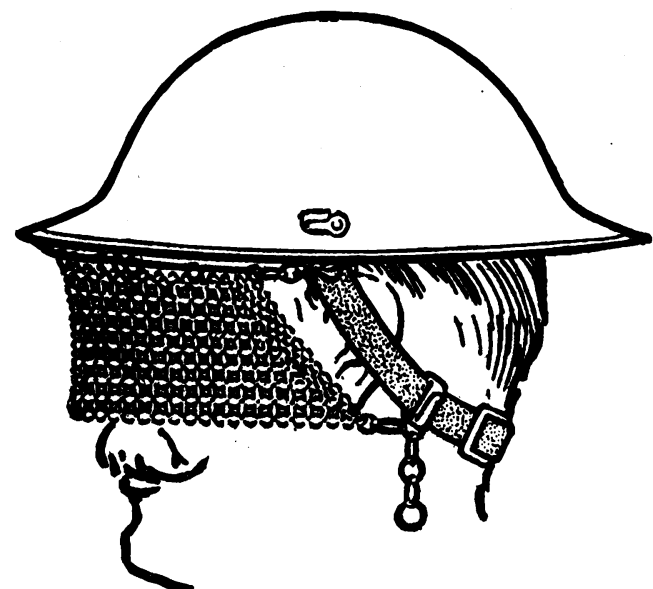

right angles to the plane of its surface; a tangential blow would meet with a practically continuous barrier of steel.

The visor is fastened to the helmet. It is therefore not a separate piece of equipment to be remembered, and attached to an already overloaded body.

When not required, the visor can be thrown up on to the brim of the helmet, and lowered again as occasion requires, by the simple process of unhooking a chain, and refastening to another hook.

A chemical process renders the links rust-proof.

\title{
PAPILLEDEMA IN RELATION TO GUNSHOT FRACTURE OF THE MANDIBLE
}

BY

\author{
G. F. C. Wallis, \\ MARGATE.
}

THE papillœdema of the optic nerve seen in the patient whose history is here recorded, presents two rather interesting features: first, in that the cause was apparently a local meningitis from infection through a traumatic fissure of the glenoid fossa; and, secondly, that the optic nerve was not involved until two months after the original wound was received, being excited in all probability by attempts to remove sequestra of the mandible. The patient is also one of the many examples this war has provided of extraordinary tenacity of life after severe injury. 
Private A. A. Mc., aged 26, was wounded at Ypres on April 26, 1916. A trench mortar bomb exploded near, from which he received no less than thirty wounds. $\mathrm{He}$ was evacuated from Boulogne, and admitted to the Fairfield Red Cross Hospital on May 4, under the care of Dr. Raven. The chief injuries were :amputation stump through the upper third of the right femur, two fingers of the left hand missing, multiple wounds of the shoulder, chest, and left arm, and the left ramus of the lower jaw shattered. This latter was a deep ragged wound extending from the malar bone downwards and backwards to the sterno-mastoid muscle. The bone was much comminuted, and the lower division of the facial nerve was severed, so that the left side of the face below the orbit was paralysed; because of the state of his jaw, nourishment could be taken only with exceeding difficulty. All the wounds were very septic, the temperature was hectic, and the general condition very grave. By May 12 a hypopyon-ulcer had developed in the right eye, for which the writer was asked to see him. Although the keratitis had only been present for three or four days, owing to the lowered vitality, the whole cornea had become affected. This eye became disorganized, and I removed it two weeks later as soon as he was sufficiently recovered to take a general anæsthetic. On the first occasion that he was seen, the left eye was carefully examined. The conjunctiva below was tattooed with burnt powder, and a piece also was embedded in the outer part of the cornea. Opposite to this the pupil was drawn to one side, but otherwise there was no sign of a perforation. The vision was full, and the fundus and media (with a dilated pupil) were normal. There was no ciliary injection, and the pupil reacted healthily. Towards the end of May, 1916, the wounds had become less septic under treatment by "Eusol" dressings, fomentations, and streptococcal vaccines. The evening temperature was now only $98^{\circ} 4^{\circ} \mathrm{F}$.

On June 20, although he had been apparently making steady progress, the fever recurred, and he began to be sick and to suffer from headache. Fragments of sequestra as they presented had been removed from the jaw-wound from time to time during the past few weeks. On June 24, when I re-examined him because he now said that the vision was failing, the pupil was contracted, but reacted normally to light; there was no iritis. Jaeger 6 could only be read with difficulty. A well-developed papillodema was present, the swelling being $+3 \mathrm{D}$. above the rest of the fundus. The surrounding retina was little involved and there were no hæmorrhages. The sickness and headaches continued occasionally and with decreasing severity to the end of July, whilst the temperature had become normal some time before this date. Throughout August and September the vision and the papillodema did not improve at all, the disc became increasingly pallid and some exudate 
appeared on the vessels at the papilla. During this time the field of vision to rough measurement remained normal. In October the œdema began to subside, and by November 27, at which date he was transferred to the Norbury Jaw Hospital, Croydon, the healthy state.was almost restored. The wound of the jaw had contracted down to a small sinus, and with the exception of one finger, all the other injuries had healed.

The long duration of the optic neuritis gave cause for considerable anxiety, lest this poor shattered wreck should lose the sight of his only eye: also, owing to the causation being somewhat obscure, it was a little difficult to know the best line of treatment to adopt.

The diagnosis.-There was no albuminuria, and no possibility of sympathetic ophthalmitis, and obviously the association of neuritis, headache, and sickness pointed to intra-cranial mischief. There was no discharge from the ear, and, in so far as could be judged in such a patient, no giddiness. Consequently, and in spite of his being completely deaf on that side (since the explosion), it did not seem at all probable that it arose from middle or inner ear suppuration. Dr. Raven and I came to the conclusion that the papillœdema had set in about the time that the attempts were made to remove the sequestra. It was therefore possible that the explosive force which had comminuted his jaw had at the same time driven the head of that bone into the glenoid fossa and caused a fracture of the base: that the interior of the skull had, at an early date, been cut off from septic matter by a fibrinous deposit, which, only when the parts were disturbed, allowed the entrance of infection. On this hypothesis a local meningitis had been caused which in turn gave rise to the classical signs of headache, sickness, and papillœdema. Accordingly it was determined to make no further efforts to remove the sequestra, but merely to keep the wound open and drained. An amelioration of the symptoms soon set in, but the papillœdema, as might be expected if due to a meningitis, was a long time in resolving.

On April 17, 1917, an opportunity presented for re-examination of this patient. The wound in the neck was now only a small sinus, and the general condition was good : by means of a specially constructed denture the jaw had been brought to the middle line, and he was now able to eat solid food with some comfort. The visual field was full for a $5 \mathrm{~mm}$. white object, and the acuity of vision $6 / 5$ and J.1. The fundus appeared normal with little or no atrophy of the nerve.

From the satisfactory progress it would appear that our assumption was correct. The importance of dealing very cautiously with a wound of this character requires no emphasis, for it is obvious that much disturbance of the parts might give rise to a fatal meningitis. 